\title{
Serial verbal learning and retention in mental defectives ${ }^{12}$
}

Using mentally retarded Ss from two different I.Q. levels, the following results were obtained: (a) speed of learning is related to intelligence level, (b) the groups do not differ on the types of errors which they commit during the learning trials and (c) once the material is learned to a fairly stringent criterion, long-term retention of both the groups is similar, regardless of initial number of trials.

The ability to retain learned material is an important aspect of the total learning process, and the mechanism of this long-term memory may be distinct from that of short-term memory. According to Broadbent (1958), incoming information is initially held in a short-term storage, and from this, part of the information is selectively passed by a hypothetical filter to a long-term store.

Researchers in the field of mental subnormality, comparing the responses of the subnormal with those of normal Ss, have argued that though the short-term memory system is impaired in the defective (Ellis, 1963), their long-term memory for well-learned material is relatively good (O'Connor \& Hermelin, 1963). The present study was concerned with comparing the learning and long-term retention of two groups of Ss representing two levels of verbal intelligence from the subnormal population. The nature of errors made by the two groups during the learning trials was also subjected to an analysis.

Subjects

Eight subnormal and eight severely subnormal male adults were selected from a Local Authority Day Training Center. The mental ages, as measured by the Peabody picture vocabulary test (Dunn, 1959) of the subnormals ranged from 110 to 130 months with a mean of 117 months, as compared to a range of mental ages from 55 to 89 months for the severely subnormal with a mean of 65 months. The difference of 52 months between the mental ages of the two groups was highly significant $(t=12.74, p<.001)$. The mean chronological ages for the groups were 22.6 and 23.3 years, respectively.

\section{Materials and Procedure}

The materials consisted of black outline drawings of eight common objects (tie, clown, case, jacket, bird, flower, clock, bus), all identifiable by the Ss. The stimuli taken in slides were projected one at a time on a screen by a Kodak Carousel, so that each item ( 4 in. sq.) was clearly visible to the $\mathrm{S}$. The serial anticipation method was adopted. A signal of red light served as the cue for guessing the first item, and the exposed item served as the cue to the one that followed. The presentation time was $2 \mathrm{sec}$ per item with $5 \mathrm{sec}$ interitem interval. The intertrial interval was 8 sec. Four trials a day were given, and the Ss were seen individually. The series was repeated until each $S$ had memorized the items in serial order to a criterion of three successive errorless reproductions. The nature of errors made during the learning trials was also recorded.

Without any prior warning, 15 days after the criterion learning each $S$ was given a retention test in the same way.

Results

So far as the learning trials are concerned, it was found that the subnormal Ss took an average of 13.12 trials to learn the series, as compared to 21.94 trials for the severely subnormal Ss. The difference was highly significant $(F=10.42, p<.01)$.

Two types of errors, transposition (correct response but sequentially misplaced) and omission (items omitted) were made by the groups during learning of the series. When total numbers of errors were compared it was found that the subnormal group made 159 transposition and 96 omission errors and that the severely subnormal group made 226 and 336 , respectively ( $X^{2}$ $=38.6, p<.001)$. But when the $x^{2}$-table was made independent by taking into account the $S$ factor, the differences became nonsignificant.

The retention test showed that the mean score of the subnormal group was 5.875 (range 4 to 8) and that of the severely subnormal group was 5.500 (range 4 to 8 ). The difference was nonsignificant $(F<1)$.

\section{Discussion}

The results showed that the speed of learning is related to the level of intelligence. Delker (1965), using junior high school students, found a similar relationship between $\mathrm{IQ}$ and trials to criterion. This is an expected result, since a close relation between intelligence and learning ability is implied in most definitions of intelligence. In fact, intelligence is frequently defined as " the ability to learn."

From the error analysis it was found that there was no difference between the groups in terms of types of errors made during learning trials. Conrad (1959), using normal Ss, found that his four best Ss made proportionately more transposition errors than the four worst Ss, who made proportionately more omission errors. However, he compared total number of errors committed by the Ss. Thus it is possible that his $\mathrm{X}^{2}$-table was not independent, since in the present 
study, similar findings were observed (i.e., $\mathrm{X}^{2}$ was significant) when total errors were compared between the groups. An inspection of the data in the present experiment revealed that one $S$ in the severely subnormal group took 69 trials and made 178 omission errors. This contributed substantially to the proportion of omission errors within that group when total errors were compared. But when the $\mathrm{x}^{2}$-table was made independent, such differences disappeared. In a previous experiment the present investigators (Sen \& Sen, 1967) showed that the personality factor of the $S$ influences the nature of the errors which he commits. However, in the present experiment the personality factor was not taken into account, and the results showed that the groups, as a whole, from two different IQ levels, did not differ significantly on the types of errors which they made in a serial learning task.

The results also demonstrated that the two groups of mental defectives with different intelligence levels, needing different numbers of trials to reach the same criterion of learning, remembered equally well after 15 days. As early as 1917, Hull showed that memory impairment found in abnormal $\mathrm{Ss}$ is caused by the failure in the acquisition phase rather than fallure in retention. He noticed that abnormal patients did not differ from normals in reproducing the materials after one week, though the former group was inferior to normal controls during acquisition. O'Connor \& Hermelin (1963), using a paired-associate task, found no significant difference in recall over one month between normals and subnormals of like mental age. The effect of "consolidation" seems germane to an interpretation of the present results. During the initial learning trials, the memory trace is in a relatively fragile condition; but with successive repetitions the trace tends to become consolidated and pass into the long-term store. Even though the number of trials required by the Ss to learn the material varied considerably, depending upon intelligence level, once it was learned to the same criterion, the degree of consolidation became, perhaps, the same. This seems to be the most likely explanation of equal long-term retention effect over a period of time. Therefore, the finding of the present experiment adds support to the view that it is the degree of learning that determines memory rather than the ease with which the material is acquired in the first place.

\section{References}

Broadbent, D. E. Perception and communication. London: Pergamon Press, 1958.

Conrad, R. Errors of immediate memory. Brit. J. Psychol., 1959, 50, 349-359.

Delker, H. A. H. The relationship between memory and intelligence among junior high school students. Dissert. Abstr., 1965, 65, 5107-5108.

Dunn, L. M. Peabody picture vocabulary test. American Guidance Service, Inc., 1959.

Ellis, N. R. The stimulus trace and behavioral inadequacy. In N. R. Ellis (Ed.), Handbook of mental deficiency. New York: McGraw-Hill, 1963. Pp. 134-158.

Hull, C. L. The formation and retention of association among the insane. Amer. J. Psychol., 1917, 28, 419-435.

$0^{\prime}$ Connor, N., \& Hermelin, B. Recall in normals and subnormals of like mental age. J. abnorm. soc. Psychol., 1963, 66, 81-84.

Sen, A. K., \& Sen, A. A study on trace inaccessibility among severely subnormal adults. J. ment. Defic. Res., 1967, 11, 31-35.

\section{Notes}

1. This paper is based on part of a thesis submitted by the first author in partial fulfillment for the Ph.D. degree at the University of Hull, England. The writers are indebted to Dr. A M. Clarke and Professor A. D. B. Clarke for their valuable suggestions and critical review of the manuscript.

2. The study was supported by a Commonwealth Scholarship awarded by the Association of Commonwealth Universities. 